\title{
Durabilidade de fachadas: método de ensaio para verificação da resistência à ação de calor e choque térmico
}

\author{
Durability of facades: test method for assessment of \\ facade resistance to heat and thermal shock
}

\section{Luciana Alves Oliveira \\ João Heitzmann Fontenelle Claudio Vicente Mitidieri Filho}

\section{Resumo \\ A}

avaliação da durabilidade de sistemas construtivos envolve a identificação dos agentes agressivos do ambiente. Em países tropicais, tende a ser significativa a ação de agentes de degradação, como altas temperaturas, umidade, radiação ultravioleta e agentes biológicos. A ação desses agentes é mais atuante nas fachadas dos edifícios, por sofrerem continuamente aquecimento, em razão da radiação solar, e resfriamento, em função de chuvas ou oscilações térmicas, fenômeno conhecido como choque térmico. No Brasil, a resistência à ação de calor e choque térmico de fachadas é tratada na norma de desempenho - NBR 15575-4 (ABNT, 2013). Entretanto, o método de ensaio proposto por esta norma difere dos métodos de ensaios de normas estrangeiras, em alguns aspectos. Assim, o objetivo deste artigo é discutir e propor revisões no método de ensaio estabelecido na norma brasileira para avaliar a resistência dos elementos de fachada leve à ação de calor e choque térmico. A discussão e proposta de revisão do método de ensaio de choque térmico são baseadas em revisão bibliográfica, e pelos resultados de ensaios realizados conforme a NBR 15.575-4 (ABNT, 2013). Foram propostas as seguintes modificações: tempo de permanência do corpo de prova na fase aquecida, e dimensões e restrições impostas ao corpo-de-prova. Para a consideração de outros aspectos, como tempo e quantidades de ciclos, estudos ainda precisam ser desenvolvidos.

Palavras-chaves: Durabilidade. Fachada. Choque térmico. Sistema construtivo. Desempenho.

Luciana Alves Oliveira Instituto de Pesquisas Tecnológicas do Estado de São Paulo São Paulo - SP - Brasil

João Heitzmann Fontenelle Instituto de Pesquisas Tecnológicas do Estado de São Paulo São Paulo - SP - Brasil

Claudio Vicente Mitidieri Filho Instituto de Pesquisas Tecnológicas do Estado de São Paulo São Paulo - SP - Brasil

Recebido em 14/03/14 Aceito em 30/09/14

\section{Abstract}

The durability assessment of building systems involves the identification of the environment degradation factors. In tropical countries, the action of degradation factors, such as high temperature, humidity, ultraviolet radiation and biologic agentstends to be significant. The action of these factors is more significant on the facades of buildings, because of continuous heating updue to ultraviolet radiation; and cooling due to rain or thermal oscillations, a phenomenon known as thermal shock. In Brazil, facade resistance to heat and thermal shock is addressed by the NBR 15575-4 (ABNT, 2013) technical standard from 2013. However, in certain aspects, the testing method proposed in this standard differs from foreign testing methods. The aim of this paper is to discuss and propose a revision of the Brazilian test method to assess light facade systems' resistance to heat and thermal shock. It is based on a literature review, and also on the tests conducted according to NBR 15575-4 (ABNT, 2013). The following changes have been proposed: time of permanence of the sample inthe heated phase, and sample dimensions and restrictions imposed to the sample. Further studies need to be conducted to examine others aspects, such as duration and number of cycles.

Keywords: Durability. Facade. Thermal shock. Constructive system. Performance. 


\section{Introdução}

Uma das exigências mais importantes e complexas quando se trata de desempenho das edificações é a durabilidade dos produtos, seja de materiais, de componentes e, principalmente, de sistemas construtivos. A durabilidade pode ser tomada genericamente como o período no qual o produto mantém as características ou funções que lhe foram atribuídas, atendendo ao desempenho esperado ao longo de sua vida útil. Pode ser entendida também como uma exigência de caráter econômico do usuário, pois está associada ao custo global do produto, considerando os custos iniciais, de manutenção e de operação ao longo do tempo. Segundo a NBR 15575-1(ABNT, 2013a),

\section{[...] é a capacidade da edificação ou de seus sistemas de desempenhar suas funções ao longo do tempo e sob condições de uso e manutenção especificadas no manual de uso, operação e manutenção [...].}

Os resultados de avaliações de durabilidade subsidiam a análise do atendimento da Vida Útil de Projeto (VUP), que é definida na NBR 15575-1 (ABNT, 2013a) como sendo

\section{[...] o período estimado de tempo para o qual um sistema (produto) é projetado, a fim de atender aos requisitos de desempenho estabelecidos, considerando os requisitos das normas aplicáveis, o estágio do conhecimento e supondo o atendimento da periodicidade $e$ correta execução dos serviços de manutenção pré-definidos [...].}

Não se trata da durabilidade do produto, mas de uma estimativa teórica do tempo de vida útil, que pode ser ou não atingida em função da eficiência das manutenções, de alterações das condições de exposição, entre outros.

A durabilidade também é importante para a realização de análises de impacto ambiental, pois, quanto maior for o ciclo de vida de um produto, menor será o consumo de recursos empregados em substituições, uma vez que essas serão menos frequentes, requerendo, portanto, menor consumo de materiais e de energia no computo geral. Em função disso, em alguns países o termo utilizado é "desenvolvimento durável", e não "desenvolvimento sustentável", conforme citado por John et al. (2002). A norma ISO 15686-6 (INTERNATIONAL..., 2004) discute e mostra a relação entre VUP e análises ambientais.

A avaliação da durabilidade de produtos e sistemas construtivos envolve, inicialmente, a definição dos agentes agressivos que mais podem afetar suas características ou propriedades ao longo do tempo. Ainda existem poucos estudos para análise da durabilidade de elementos construtivos, como uma parede ou uma cobertura; a maioria dos estudos trata de ensaios nos materiais ou componentes, como mostram os artigos de Dias (2005), Jonh e Sato (2006) e Daniotti e Cecconi (2014). Apesar das dificuldades, inclusive de interpretação de resultados de ensaios, a avaliação da durabilidade de um sistema construtivo deve considerar os agentes que afetam não só os componentes isoladamente, mas, principalmente, o conjunto integrado por esses componentes.

Lewry e Crewdson (1994) discutem quatro métodos para avaliar a durabilidade de materiais, componentes ou sistemas construtivos, sendo possível adotar um ou mais métodos:

(a) ensaios comparativos (benchmark tests),por meio do uso de dados conhecidos sobre a durabilidade dos componentes, em certas condições de exposição;

(b) ensaios comparativos com uso de material de referência, os quais podem ser utilizados para calibrar tanto equipamentos quanto para comparar resultados de ensaios entre um componente de referência e, por exemplo, um componente inovador (aquele cujo comportamento ao longo do tempo, em certas condições de exposição, não é conhecido);

(c) ensaios mecânicos realizados antes e após exposição do componente a agentes de degradação (ensaio de envelhecimento acelerado, por exemplo, com o uso de câmara "Weather-O-Meter"); e

(d) ensaios para avaliar o comportamento em condições de uso real do edifício, ou seus componentes (ensaios in situ - envelhecimento natural).

Esses autores expõem que a abordagem de desempenho deve ser baseada em:

(a) consideração dos fatores que podem afetar a durabilidade;

(b) ensaios de envelhecimento acelerado, para definir os principais fatores de degradação e os mecanismos dessa degradação; e

(c) análise das principais causas de degradação considerando-se a função do produto e o ambiente de uso.

Jonh e Sato (2006) também propõem as seguintes estratégias: ensaios de envelhecimento natural, ensaios de envelhecimento acelerado e estudos em campo (acompanhamento do produto em escala e condições de uso real). Esses autores expõem também que (JONH; SATO, 2006), 
[...] a durabilidade não é uma propriedade do material, mas o resultado da interação entre o material e o ambiente que o cerca, incluindo aspectos de microclima [...].

Assim, um mesmo material, componente ou sistema pode apresentar desempenho diferente notempo para diferentes condições de exposição.

Como o Brasil é um país tropical, alguns agentes de degradação são mais significativos do que em países como os EUA, o Canadá e aqueles do Norte da Europa, particularmente no que diz respeito a altas temperaturas, umidade, radiação ultravioleta e agentes biológicos, como cupins e fungos (ARNOULT; KREMP; MUSEMBI, 1995). Por exemplo, em São Paulo, Brasil, a média anual das temperaturas máximas é de $24,9^{\circ} \mathrm{C}$, e das mínimas, de $15,5^{\circ} \mathrm{C}$, com média de $1.590 \mathrm{~mm}$ de precipitação ${ }^{1}$. Em Paris, França, a média anual das temperaturas máximas é de $15^{\circ} \mathrm{C}$, e das mínimas, de $8^{\circ} \mathrm{C}$, com média de $630 \mathrm{~mm}$ de precipitação ${ }^{2}$.

O comportamento diante dessas ações (altas temperaturas, umidade, radiação solar, etc.) é particularmente significativo nos componentes localizados nas coberturas e nas fachadas dos edifícios, por serem continuamente aquecidas pelos raios solares e sofrerem também resfriamento em razão da ocorrência de chuvas ou de mudanças de temperatura do ambiente. Portanto, um dos aspectos importantes para o estudo da durabilidade de fachadas é seu comportamento ante ciclos de altas temperaturas superficiais e de resfriamentos bruscos. Se a temperatura a que estiver exposto um componente variar rapidamente, ou seja, se ele for submetido a um "choque térmico", será produzida uma diferença de temperatura entre a superfície do corpo e seu interior, que poderá provocar tensões de elevada magnitude. Tal fenômeno afeta os sistemas de fachadas, particularmente os sistemas leves (com pequena inércia térmica) e aqueles compostos de várias camadas, com elementos não homogêneos.

Griciute, Bliudzius e Norvaisiene (2013) mostram a relação entre os métodos para estimar a vida útil de serviço, os métodos de ensaios acelerados, como a ação de calor e choque térmico, e as condições climáticas locais, também considerando um sistema leve de multicamadas, como o Exterior Insulated Facade System (EIFS, sigla americana) ou o External Thermal Insulation Composite Systems (ETIC, sigla europeia).

${ }^{1}$ Dados médios de três anos. Disponível

em:<http://www.inmet.gov.br/portal/index.php?r=clima/norma isClimatologicas>. Acesso em: 7 jul. 2014.

${ }^{2}$ Dados médios de três anos. Disponível em:

<http://www.meteo-paris.com/ile-de-

france/climat.html>.Acesso em: 4 jul. 2014.
Várias normas estrangeiras avaliam o comportamento dos componentes de paredes quanto à ação de calor e choque térmico, como a C1185-8 (AMERICAN..., 2012), a ETAG 004 (EUROPEAN..., 2008) e a AS/NZS 2908 (AUSTRALIAN..., 2000), originada da ISO 8336 de 1993, cuja versão atual é de 2009. Tais normas consideram que a avaliação é feita por meio de um ensaio que mede a "fadiga" de um corpo de prova submetido a ciclos de intensa ação de calor e choque térmico, sendo, portanto, considerado um ensaio de envelhecimento acelerado. O princípio do ensaio é submeter a superfície do corpo de prova a uma situação de tensões passíveis de ocorrer nos sistemas de vedações verticais, em situações normais de uso.

Segundo Esquivel (2009), um dos ensaios de laboratório mais utilizados na análise dos efeitos do choque térmico é aquele que prevê o resfriamento do corpo de prova, previamente aquecido, com água na temperatura ambiente, geralmente por imersão ou aspersão.

No Brasil, o requisito de resistência à ação de calor e choque térmico é estabelecido para os sistemas de fachada na parte 4 da NBR 15575 (ABNT, 2013b). O critério de avaliação é a ausência de fissuras ou falhas que possam comprometer o desempenho do sistema de vedação, durante e após os ciclos de ensaio, e a limitação do deslocamento horizontal do corpo de prova. $\mathrm{O}$ ensaio, segundo a NBR 15575-4 (ABNT, 2013b), deve ser realizado em um corpo de prova com no mínimo 1,20 m de comprimento, e altura equivalente ao pé-direito da edificação, considerando todos os detalhes construtivos da parede em uso, como as juntas. O equipamento de ensaio é constituído por uma fonte radiante vertical, um conjunto de sensores térmicos instalados no corpo de prova e acoplados a um equipamento de aquisição automática de dados, e um sistema de aspersão de água para resfriamento do corpo de prova.

Entretanto, o método de ensaio proposto pela norma brasileira difere em alguns aspectos dos métodos de ensaios de algumas normas estrangeiras; por exemplo, a temperatura máxima da superfície exposta do corpo de prova: na NBR $15575-4$ (ABNT, 2013b) é de $(80 \pm 3)^{\circ} \mathrm{C}$, na ETAG 004 (EUROPEAN..., 2008) é de $(70 \pm 5)^{\circ} \mathrm{C}$ e na ASTM C1185-8 (AMERICAN..., 2012) e na ISO 8336 (INTERNATIONAL..., 2009) é de (60 \pm $5)^{\circ} \mathrm{C}$. Além dessas diferenças, existem variações quanto ao método de medição da temperatura, sendo na norma brasileira especificada a medição por meio de termopares diretamente acoplados à superfície externa do elemento de vedação, enquanto pela ASTM os termopares são fixados 
em pequenas placas metálicas pintadas de preto, utilizadas como placas de referência, que são fixadas na superfície do corpodeprova.

Kingery $\left(1955^{3}\right.$ apud ESQUIVEL, 2009) classifica os modelos experimentais de choque térmico em função da forma como o gradiente térmico é simulado - por exemplo, aquecimento ou resfriamento rápido, ou ciclos de variação de temperatura - e da forma como é avaliada a resistência do material em função das tensões térmicas geradas na exposição ao choque térmico, isto é, pela perda de peso, pela perda de resistência ou pelo decréscimo nas propriedades elásticas do material.

Nesse sentido, um estudo dos procedimentos ou métodos de ensaio que afetam o comportamento do elemento construtivo submetido à ação de calor e choque térmico é fundamental, pois pode levar a diferentes conclusões quanto à durabilidade.

Nos ensaios realizados no Brasil algumas discussões são importantes para melhor representar as solicitações ou as condições de exposição do corpo de prova, devendo-se destacar:

(a) a necessidade de redução da temperatura máxima a que é submetida a superfície do corpo de prova, para aqueles materiais cuja temperatura de distorção (HDT) ${ }^{4}$ seja inferior aos $80^{\circ} \mathrm{C}$, como os plásticos (condição a ser considerada no caso de a medição da temperatura ser realizada diretamente na superfície do corpo de prova);

(b) a inclusão do intervalo de tempo (mínimo) para elevar a temperatura da superfície do corpo de prova, procurando-se nesse contexto representar da melhor forma possível as condições que ocorrem no ambiente;

(c) o tempo de permanência do corpo de prova ensaiado na fase aquecida;

(d) a vinculação do corpo de prova em suas laterais, além do topo e da base, visando criar condições mais reais de contorno, já que as restrições impostas aos livres movimentos de expansão e contração do material interferem diretamente nos resultados obtidos; e

(e) o aumento do comprimento do corpo de prova, de forma a permitir melhor reprodução dos detalhes construtivos, como as juntas, e também do comportamento da parede.

${ }^{3}$ KINGERY, W. D. Factors Affecting Thermal Stress Resistance of Ceramic Materials. Journal of the American Ceramic Society, Easton, v. 38, n. 1, p. 3-15, 1955.

${ }^{4} \mathrm{HDT}$ - Heat Distortion Temperature-Temperatura-limite que o material pode suportar sem começar a perder suas propriedades mecânicas.
Assim, o objetivo deste artigo é discutir e propor revisões no método de ensaio estabelecido na NBR 15575-4 (ABNT, 2013b) para avaliar a resistência dos elementos de fachada leve à ação de calor e choque térmico, visando melhorar e padronizar a forma de executar um dos ensaios mais significativos para avaliação da durabilidade dos elementos de fachada leves, ou fachadas com multicamadas, em países tropicais como o Brasil.

$\mathrm{O}$ artigo está estruturado da seguinte maneira: introdução e objetivo; métodos de ensaio e pesquisa experimental; apresentação e análise dos resultados de ensaios; análise e proposição de parâmetros a serem considerados para os métodos de ensaio de ação de calor e choque térmico no Brasil; e considerações finais.

\section{Métodos de ensaio e pesquisa experimental}

A discussão e a proposta de revisão do método de ensaio de ação de calor e choque térmico estão baseadas em revisão bibliográfica e são também justificadas pela análise dos resultados de alguns ensaios realizados conforme o método previsto na norma NBR 15575-4 (ABNT, 2013b), sendo os ensaios realizados na forma original da norma e com modificações cogitadas. Considerou-se, também, o aprendizado obtido nos ensaios realizados por Fontenelle (2012).

A revisão bibliográfica foi feita considerando-se artigos técnicos, normas nacionais e estrangeiras sobre o tema, com maior aprofundamento nas normas estrangeiras que tratam de métodos de ensaio de choque térmico. Selecionaram-se três normas, a NBR 15575-4 (ABNT, 2013b), a C1185-8(AMERICAN..., 2012) e a ETAG 004 (EUROPEAN..., 2008), sendo esta última uma diretriz para o projeto e a avaliação, e não uma norma técnica propriamente dita.

A NBR 15575-4 (ABNT, 2013b) é a norma brasileira que especifica requisitos e critérios de desempenho para as vedações verticais, incluindo os critérios com relação à resistência à ação de calor e choque térmico e seu respectivo método de ensaio. Portanto, a análise comparativa é feita entre os métodos da ASTM e da ETAG com o previsto na norma brasileira.

A C1185-8 (AMERICAN..., 2012) foi adotada para análise, pois é uma norma bastante difundida na América do Norte e orienta muitos dos métodos de ensaio de normas brasileiras, além da similaridade com o método de ensaio proposto na ISO 8336 (INTERNATIONAL..., 2009), norma de abrangência internacional. A C1185-8 (AMERICAN..., 2012) tem um aspecto 
interessante, porque, apesar de ser específica para chapas cimentícias planas, estabelece que o ensaio de choque térmico seja feito em trecho de parede executada em situação real, incluindo juntas.

A ETAG 004 (EUROPEAN..., 2008) é uma diretriz europeia para um sistema de vedação leve (ETIC), na qual são estabelecidos os requisitos e critérios de desempenho que as fachadas precisam cumprir, incluindo também os critérios com relação à resistência à ação de calor e choque térmico e o respectivo método de ensaio.

Quanto aos ensaios realizados, o objetivo principal foi mostrar que os resultados são diferentes dependendo das condições adotadas com relação às dimensões dos corpos de prova (trechos de parede) e das restrições laterais impostas ao trecho de parede ensaiado.

Portanto, foram realizados ensaios de choque térmico considerando três tipos de fachadas leves, denominadas parede 1 , parede 2 e parede 3 . A parede 1 é estruturada por perfis de aço conformados a frio (perfis leves de aço), com fechamento em chapas cimentíciasnas faces internas e externas (multicamada), fixadas aos perfis por parafusos. O ensaio da parede 1 foi realizado conforme o método de ensaio previsto na NBR 15575-4 (ABNT, 2013b).

A parede 2 é similar à parede 1 , porém com diferença em relação ao tratamento das juntas entre placas de fechamento externo, além da adoção de placas externas (chapas cimentícias) com coeficiente de variação higroscópicamenor do que o das chapas da parede 1 . O ensaio da parede 2 foi realizado considerando-se o método de ensaio da NBR 15575-4 (ABNT, 2013b), com algumas modificações com relação às dimensões do corpo de prova e aos vínculos laterais (restrição da movimentação lateral do trecho de parede ensaiado). Assim, o ensaio realizado na parede 2 é potencialmente mais rigoroso que o ensaio realizado na parede 1 . Para ambas as paredes (1 e 2), além da realização dos ensaios de ação de calor e choque térmico, foram feitas verificações do comportamento de um protótipo, ou seja, observações relativas ao surgimento de eventuais falhas que comprometessem a durabilidade do protótipo construído em escala real.

Os protótipos foram construídos com o objetivo principal de acompanhar aspectos do procedimento de construção e verificar o comportamento das paredes ao longo do tempo, além de avaliar a coerência entre os resultados dos ensaios de envelhecimento feitos no laboratório (choque térmico) e o envelhecimento natural. Entretanto, não foi escopo do presente trabalho coletar dados precisos dos agentes de degradação que afetaram cada protótipo e, por isso, não foram estabelecidas correlações entre os resultados dos ensaios de choque térmico e as observações em campo.

Para a parede 3 , formada por isolante térmico rígido e revestimento estruturado de argamassa, as avaliações foram feitas somente pela análise de dois ensaios de choque térmico. Os dois ensaios realizados seguiram o método da NBR 15575-4 (ABNT, 2013b), porém com modificações no que diz respeito às vinculações laterais. No primeiro ensaio, o corpo de prova tinha $1,20 \mathrm{~m}$ de comprimento, no segundo ensaio, $2,40 \mathrm{~m}$.

O método de ensaio da NBR 15575-4 (ABNT, 2013b) estipula o aquecimento por radiação (com lâmpadas ou resistências elétricas) de um trecho de parede com comprimento mínimo de $1,20 \mathrm{~m}$ e altura equivalente ao pé-direito, até atingir uma temperatura superficial de $80^{\circ} \mathrm{C}$, controlada com termopares posicionados na própria face do corpo de prova. O corpo de prova é mantido nessa temperatura durante $1 \mathrm{~h}$, promovendo-se, em seguida, o resfriamento via jato de água (simulação da chuva) até atingir uma temperatura superficial de aproximadamente $20^{\circ} \mathrm{C}$. São realizados 10 ciclos de ensaio (aquecimento e resfriamento brusco), durante os quais são verificadas eventuais ocorrências no corpo de prova, como fissuras, destacamentos, empolamentos, delaminações, manchas de umidade e outras que podem comprometer o desempenho, além de registrar-se o deslocamento horizontal do corpo de prova, tomando-se essa medida na face oposta à face submetida à ação do calor e da água. No método de ensaio modificado foram testados corpos de prova com $1,20 \mathrm{~m}$ e com $2,40 \mathrm{~m}$ de comprimento, vinculando-se, por meio de parafusos, as laterais do corpo de prova em perfis de aço ou de madeira, ou seja, introduzindo-se restrições às movimentações higrotérmicas e procurando-se, dessa forma, simular o que pode ocorrer em situações normais de uso.

A Tabela 1 resume as avaliações feitas para as paredes 1, 2 e 3, em função dos métodos de ensaio adotados. As Figuras 1 e 2 ilustram os trechos da parede 3 com $1,20 \mathrm{~m}$ e com 2,40m de comprimento, ambas com restrição nas laterais (perfil de madeira aparafusado em cada lateral dos trechos de parede ensaiados). 
Tabela 1- Resumo das condições dos ensaios realizados

\begin{tabular}{|c|c|c|c|c|c|}
\hline $\begin{array}{c}\text { Fachada/ } \\
\text { parede leve }\end{array}$ & $\begin{array}{c}\text { Comprimento } \\
\text { do trecho de } \\
\text { parede } \\
\text { ensaiado }\end{array}$ & $\begin{array}{c}\text { Altura do } \\
\text { trecho de } \\
\text { parede } \\
\text { ensaiado }\end{array}$ & $\begin{array}{l}\text { Restrição da } \\
\text { movimentação } \\
\text { lateral do } \\
\text { trecho de } \\
\text { parede }\end{array}$ & $\begin{array}{l}\text { Método de } \\
\text { ensaio }\end{array}$ & $\begin{array}{l}\text { Verificação do } \\
\text { comportamento } \\
\text { das paredes em } \\
\text { escala e condições } \\
\text { de uso real } \\
\text { (protótipo) }\end{array}$ \\
\hline Parede 1 & $1,20 \mathrm{~m}$ & $2,60 \mathrm{~m}$ & não & $\begin{array}{c}\text { NBR 15575-4 } \\
\text { (ABNT, } \\
2013 \mathrm{~b})\end{array}$ & Sim \\
\hline Parede 2 & $2,40 \mathrm{~m}$ & $2,60 \mathrm{~m}$ & $\operatorname{sim}$ & $\begin{array}{l}\text { NBR 15575-4 } \\
\text { (ABNT, } \\
\text { 2013b), com } \\
\text { modificações }\end{array}$ & Sim \\
\hline Parede $3 \mathrm{a}$ & $1,20 \mathrm{~m}$ & $2,60 \mathrm{~m}$ & $\operatorname{sim}$ & \multirow{2}{*}{$\begin{array}{l}\text { NBR 15575-4 } \\
\text { (ABNT, } \\
\text { 2013b), com } \\
\text { modificações }\end{array}$} & Não \\
\hline Parede $3 b$ & $2,40 \mathrm{~m}$ & $2,60 \mathrm{~m}$ & $\operatorname{sim}$ & & Não \\
\hline
\end{tabular}

Figura 1 - Trecho da parede 3a com 1,20m de comprimento, com restrição nas laterais, sendo preparada para ser submetida ao ensaio de ação de calor e choque térmico

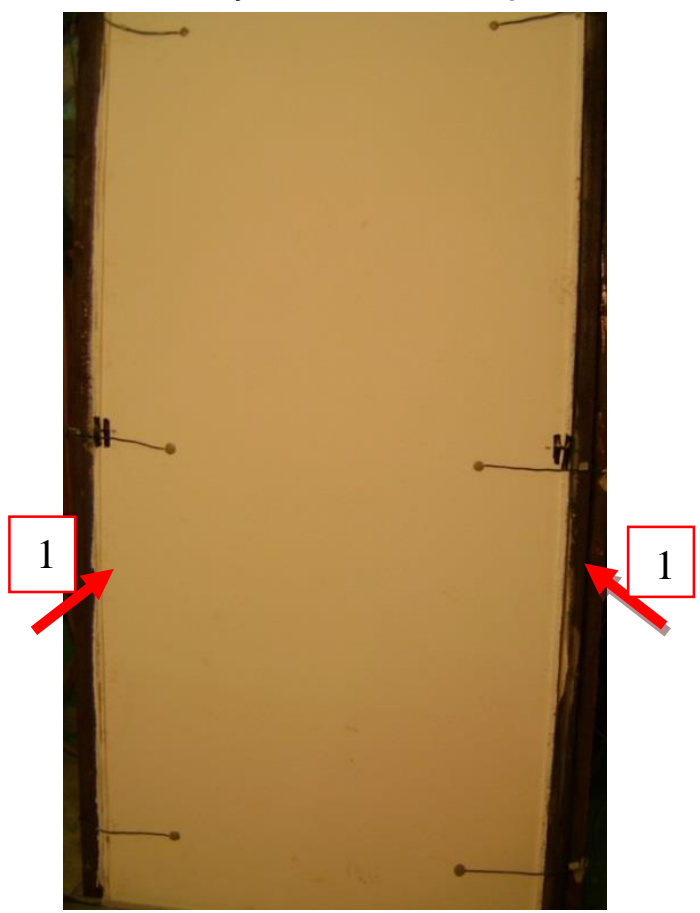

Nota: 1 Peça de madeira aparafusada à parede e fixada ao piso restringindo movimentação lateral. 
Figura 2 - Trecho da parede $3 \mathrm{~b}$ com 2,40m de comprimento, com restrição nas laterais, sendo preparada para ser submetida ao ensaio de ação de calor e choque térmico

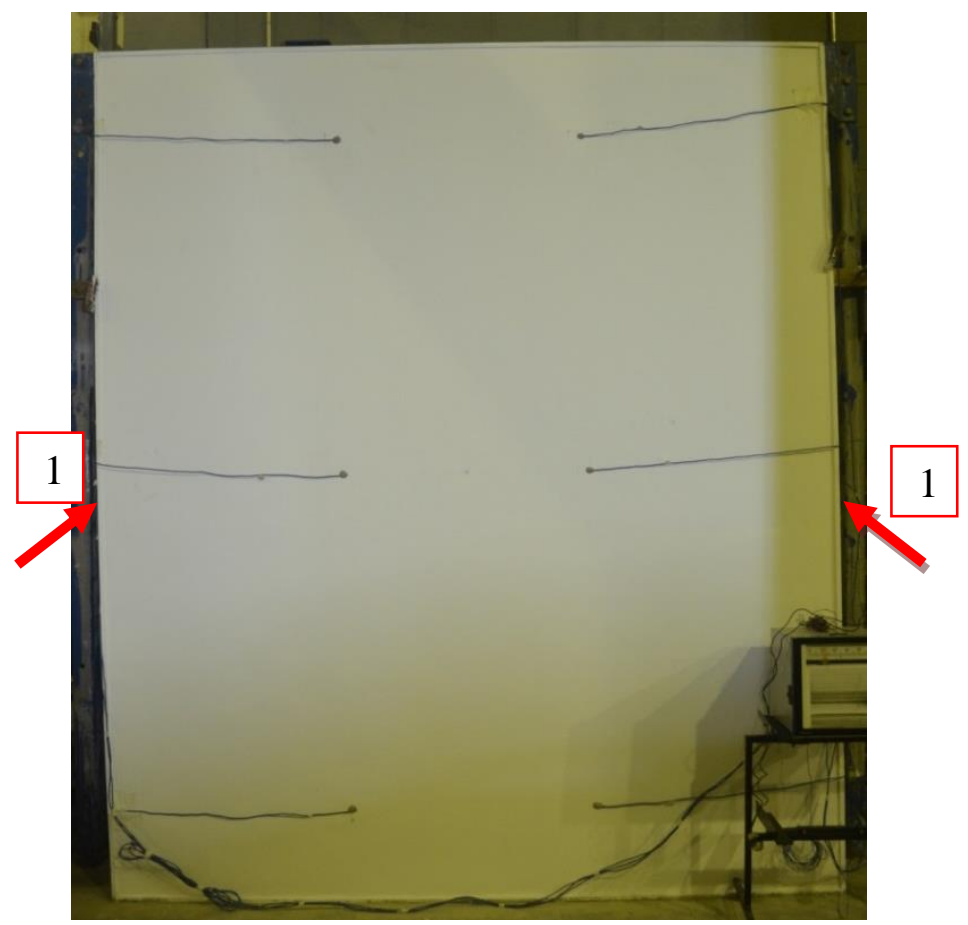

Nota: 1 Peça de madeira aparafusada à parede e fixada ao piso restringindo movimentação lateral.

\section{Apresentação e análise dos resultados de ensaios}

A Tabela 2 resume os resultados dos ensaios realizados nos três tipos de paredes, nas condições apresentadas na Tabela 1.

Um trecho da parede 1 foi submetido ao ensaio de choque térmico, com $1,20 \mathrm{~m}$ de comprimento e altura do pé-direito, sem restrição nas laterais, sendo o resultado do ensaio considerado satisfatório, uma vez que não surgiram falhas que pudessem comprometer o desempenho. Porém, o protótipo construído em campo apresentou falhas nas paredes em menos de 6 meses após sua construção. Uma modificação do sistema de placas e de juntas foi introduzida na parede 1 , resultando na parede 2 , sendo novos ensaios realizados. $\mathrm{O}$ ensaio no trecho de parede 2 foi realizado com 2,40m de comprimento, com restrição nas laterais, sendo seu resultado considerado satisfatório. No protótipo construído com a parede 2não foram observadas falhas nas inspeções feitas após 6 meses e após 1 ano de sua construção. Tais resultados indicam que o ensaio na parede 1 não conseguiu reproduzir as solicitações existentes em condições reais de exposição, uma vez que se verificou resultado satisfatório no laboratório, masnão satisfatório no campo. No caso da parede 2 , considera-se que o ensaio realizado em um trecho de parede maior e com restrições nas laterais reproduziu melhor a realidade, verificandose maior congruência entre os resultados de laboratório e de campo. Esses resultados corroboram experiências anteriores vivenciadas para outros tipos de produtos e ensaios realizados.

Quanto à parede 3, dois ensaios de choque térmico foram realizados, considerando-se um corpo de prova com 1,20m de comprimento (3a) e outro com 2,40m de comprimento (3b), ambos com restrição de movimentação nas laterais. Somente o corpo de prova com 2,40m de comprimento apresentou falhas durante a realização do ensaio, provavelmente em função da maior amplitude das movimentações higrotérmicas, decorrentes da exposição ao calor e ao choque térmico, e, consequentemente, da introdução de maiores tensões.

Assim, os resultados dos ensaios de choque térmico mostram que as paredes leves, quando ensaiadas com largura de $1,20 \mathrm{~m}$ e sem vínculos laterais, estão sujeitas a tensões menores do que quando ensaiadas com largura de 2,40m e vinculação lateral, observando-se no segundo caso incidência mais pronunciada de falhas no corpo de prova, que poderão comprometer o desempenho do elemento construtivo. Obviamente, a situação proposta de vínculos laterais e maior extensão do corpo de prova é mais rigorosa que a situação prevista no método de ensaio adotado atualmente na NBR 15575-4 (ABNT, 2013b). 
Tabela 2- Resumo dos resultados dos ensaios e da verificação do comportamento dos protótipos

\begin{tabular}{c|c|c|c}
\hline $\begin{array}{c}\text { Fachada/ } \\
\text { parede leve }\end{array}$ & Método de ensaio & Resultados dos ensaios & $\begin{array}{c}\text { Resultado da verificação do } \\
\text { comportamento da fachada } \\
\text { no protótipo }\end{array}$ \\
\hline \multirow{2}{*}{1} & $\begin{array}{c}\text { NBR 15575-4 } \\
\text { (ABNT, 2013b), } \\
\text { sem modificações }\end{array}$ & $\begin{array}{c}\text { Os resultados indicaram que os } \\
\text { critérios de desempenho foram } \\
\text { atendidos }\end{array}$ & $\begin{array}{c}\text { Surgimento de fissuras na } \\
\text { região das juntas e deformação } \\
\text { das chapas de fechamento }\end{array}$ \\
\hline \multirow{2}{*}{2} & \multirow{2}{*}{$3 \mathrm{NBR} 15575-4$} & $\begin{array}{c}\text { Os resultados indicaram que os } \\
\text { critérios de desempenho foram } \\
\text { atendidos, após introdução de } \\
\text { melhorias }\end{array}$ & Não foram observadas falhas \\
\cline { 3 - 4 } & \multirow{2}{*}{ com modificações } & $\begin{array}{c}\text { Os resultados indicaram que os } \\
\text { critérios de desempenho foram } \\
\text { atendidos }\end{array}$ & \\
\cline { 3 - 4 } & \multirow{2}{*}{$3 \mathrm{~b}$} & $\begin{array}{c}\text { Não foram atendidos os } \\
\text { critérios de desempenho, em } \\
\text { razão do surgimento de fissuras }\end{array}$ & \\
\hline
\end{tabular}

No caso de aplicações reais, as fachadas leves com chapas delgadas têm suas movimentações higrotérmicas restringidas, pois as bordas, em geral, são vinculadas à estrutura principal ou a outros elementos construtivos. Diferentemente do comportamento real, no caso do corpo de prova de $1,20 \mathrm{~m}$, com junta coincidente com seu eixo vertical, os trechos de parede têm comprimentos relativamente pequenos, de $0,60 \mathrm{~m}$, e podem movimentar-se quase que livremente, pois não há vinculação lateral. Dessa forma, as tensões introduzidas não são tão significativas, não representando corretamente a realidade. Já no caso do corpo de prova de $2,40 \mathrm{~m}$, considerando que havia uma junta intermediária e a vinculação lateral, introduziu-se maior restrição aos movimentos e, consequentemente, maiores tensões por efeito das variações de temperatura e umidade. Em suma, como a variação dimensional absoluta é proporcional à dimensão do corpo de prova, seja por efeito de temperatura ou de umidade, quanto maior a dimensão, maior a variação dimensional absoluta e, consequentemente, maiores as tensões internas introduzidas, com maior possibilidade de ocorrência de falhas.

Observações anteriores, decorrentes do histórico de ensaios, indicam que os corpos de prova de maiores dimensões e com vínculos laterais realmente simulam melhor a realidade das obras, comportamento ratificado pelos resultados dos ensaios de estanqueidade à água, realizados antes e após o ensaio de ação de calor e choque térmico. No caso em questão, como um elemento complementar de análise, também foi realizado o ensaio de estanqueidade à água nos corpos de prova das paredes do tipo 3, conforme método de ensaio prescrito na NBR 15575-4 (ABNT, 2013b), visando avaliar o comportamento da parede antes e após a submissão ao ensaio de choque térmico. No caso particular, os resultados de estanqueidade à água foram satisfatórios em ambas as situações, antes e após envelhecimento pela realização de ensaio de choque térmico, a despeito de os corpos de prova com comprimento de 2,40m terem apresentado maior incidência de fissuras superficiais.Esse assunto tem sido tratado no Sistema Nacional de Avaliação Técnica de produtos inovadores (SiNAT), vinculado ao Programa Brasileiro da Qualidade e Produtividade no Habitat (PBQP-H), já havendo consenso da introdução de tais aperfeiçoamentos no método de ensaio de choque térmico em diretrizes de avaliação técnica, como a Diretriz SiNAT 003, revisão 01 (MINISTÉRIO..., 2012).

\section{Parâmetros para o método de ensaio de ação de calor e choque térmico: análise e proposição}

Com base em revisão bibliográfica e em experiências de ensaios realizados pelos autores do presente artigo, considerando-se também resultados de análises anteriores e discussões conduzidas no Comitê Técnico do SiNAT, listamse os principais aspectos considerados significativos para ser aprimorados no método de ensaio de ação de calor e choque térmico:

(a) forma de medição da temperatura de aquecimento (na face do corpo de prova, ou em dispositivo ou corpo de prova de referência);

(b) temperatura máxima superficial a ser considerada no ensaio; 
(c) tempo de permanência do corpo de prova na fase aquecida;

(d) tempo para atingir a temperatura máxima superficial prevista no ensaio;

(e) variação da temperatura entre o centro e as bordas do corpo de prova;

(f) intensidade da energia da fonte $\left(\mathrm{W} / \mathrm{m}^{2}\right)$;

(g) vazão da água de resfriamento;

(h) temperatura da água de resfriamento, tempo e forma de medição;

(i) distribuição superficial e tempo de aspersão da água;

(j) velocidade em que a variação da temperatura ocorre;

(k) quantidade e tempo dos ciclos de ensaio e intervalo entre cada ciclo, considerando tempo de estabilização entre aquecimento e resfriamento;

(1) dimensões do corpo de prova;

(m) restrição de movimentação das laterais do corpo de prova; e

(n) cor da face externa do corpo de prova (face exposta ao ensaio).

A Tabela 3 resume as diferenças de parâmetros adotados nos métodos de ensaios de normas estrangeiras e brasileiras com relação a alguns desses aspectos anteriormente explicitados.

A seguir, são discutidos os aspectos e respectivos parâmetros relativos à categoria "corpo de prova", apesar de já terem sido parcialmente discutidos anteriormente, do ponto de vista da análise dos resultados de ensaios. Também são discutidas e propostas revisões com relação aos aspectos de "aquecimento" do corpo de prova, baseando-se na possibilidade de reproduzir algumas condições de exposição em função das características climáticas brasileiras.

\section{Aspectos relativos à definição do corpo de prova}

A NBR 15575-4 (ABNT, 2013b), conforme já abordado, estabelece o comprimento mínimo de $1,20 \mathrm{~m}$ e a altura equivalente ao pé-direito para o corpo de prova submetido ao ensaio de choque térmico, independentemente do tipo de sistema construtivo. Considerando-se o pé-direito usual de 2,60 m, o corpo de prova terá área mínima de 3,12 $\mathrm{m}^{2}$; considerando-se o pé-direito mínimo estabelecido na NBR 15575-1 (ABNT, 2013b), o corpo de prova terá área mínima de $3,0 \mathrm{~m}^{2}$. A
Diretriz SiNAT 003, revisão 01 (MINISTÉRIO... 2012), destinada a vedações leves estruturadas por perfis metálicos, recomenda a adoção de $2,40 \mathrm{~m}$ de comprimento, também com altura equivalente ao pé-direito. Nessa situação, considerando um pédireito de 2,60 m, o corpo de prova terá área de $6,24 \mathrm{~m}^{2}$. Considerando um pé-direito mínimo de 2,50 m, o corpo de prova terá área mínima de 6,0 $\mathrm{m}^{2}$. A norma C 1185-8 (AMERICAN..., 2012), que define o método para avaliação de sistemas constituídos por vedações de placas de fibrocimento sem amianto, estabelece para o corpo de prova uma área de $3,5 \mathrm{~m}^{2}$. Já a Diretriz ETAG 004 (EUROPEAN..., 2008) especifica uma área mínima de $6,0 \mathrm{~m}^{2}$.

Como os corpos de prova precisam corresponder à situação real de instalação, ou seja, no caso de painéis com ao menos uma junta no centro do corpo de prova, a largura mínima de 2,40m é sugerida, pois a modulação das placas cimentícias (componentes esses geralmente utilizados em fachadas leves) é de 1,20m, por exemplo. Assim, o painel para ensaio teria $2,40 \mathrm{~m}$ de comprimento, com pelo menos uma junta central, simulando um trecho de parede com uma junta. No caso de outras modulações de chapas, sugere-se seguir sua modulação, respeitando uma área de corpo de prova de no mínimo $6,0 \mathrm{~m}^{2}$, para que seja respeitado o pé-direito mínimo de $2,50 \mathrm{~m}$, previsto na NBR 15575-1 (ABNT, 2013a). Justifica-se essa proposta também pelos resultados dos ensaios e experimentos apresentados neste artigo.

Além da discussão das dimensões do corpo de prova, é preciso avaliar a adoção de restrição das bordas laterais do trecho de parede a ser ensaiado. A restrição à movimentação das bordas do corpo de prova é uma alternativa para aumentar a proximidade da situação de ensaio com a situação real à qual as paredes serão submetidas.

Segundo Esquivel (2009), a resposta do material ao choque térmico também está relacionada a suas condições de contorno, por isso, se houver restrições externas à livre deformação do sólido, o estado de tensões será agravado.

Assim, visando simular a realidade da instalação, sugere-se adotar a restrição das bordas laterais do trecho de parede a ser ensaiado, visto que, na prática, as paredes de fachadas não têm bordas livres. Essa restrição pode ocorrer com a execução de outro trecho de parede perpendicular à parede a ser ensaiada, ou com a inserção de perfis/colunas nas extremidades do corpo de prova, com a largura ou espessura no mínimo igual à do corpo de prova. 
Tabela 3 - Diferenças de parâmetros adotados entre os métodos de ensaios de normas estrangeiras e brasileira

\begin{tabular}{|c|c|c|c|c|}
\hline \multirow[b]{2}{*}{ Categoria } & \multirow[b]{2}{*}{ Parâmetros } & \multicolumn{3}{|c|}{ Detalhamento dos parâmetros } \\
\hline & & $\begin{array}{c}\text { NBR } 15575-4 \text { (ABNT, } \\
2013 b)\end{array}$ & $\begin{array}{c}\text { C1185-8 (AMERICAN..., } \\
\text { 2012) e ISO 8336 } \\
\text { (INTERNATIONAL..., } \\
\text { 2009) }\end{array}$ & $\begin{array}{c}\text { ETAG } \\
\text { 004(EUROPEAN..., } \\
\text { 2008) }\end{array}$ \\
\hline \multirow{5}{*}{ Aquecimento } & $\begin{array}{l}\text { Método de medição da } \\
\text { temperatura do ensaio }\end{array}$ & $\begin{array}{c}\text { Medição direta, feita } \\
\text { por meio de } \\
\text { termopares } \\
\text { posicionados sobre a } \\
\text { superfície aquecida do } \\
\text { corpo de prova }\end{array}$ & $\begin{array}{c}\text { Medição indireta - } \\
\text { medida em corpo de } \\
\text { prova de referência/placa } \\
\text { metálica preta }\end{array}$ & $\begin{array}{c}\text { Medição direta, feita } \\
\text { por meio de } \\
\text { termopares } \\
\text { posicionados sobre a } \\
\text { superfície aquecida } \\
\text { do corpo de prova }\end{array}$ \\
\hline & $\begin{array}{l}\text { Tempo para atingir a } \\
\text { temperatura de } \\
\text { aquecimento máxima }\end{array}$ & Não estabelecido & Não estabelecido & 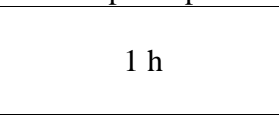 \\
\hline & $\begin{array}{c}\text { Temperatura máxima } \\
\text { do ensaio }\end{array}$ & $(80 \pm 3)^{\circ} \mathrm{C}$ & $(60 \pm 5)^{\circ} \mathrm{C}$ & $(70 \pm 5)^{\circ} \mathrm{C}$ \\
\hline & $\begin{array}{c}\text { Tempo de } \\
\text { permanência na fase } \\
\text { aquecida }\end{array}$ & $1 \mathrm{~h}$ & $2 \mathrm{~h} 55 \mathrm{~min}$ & $2 \mathrm{~h}$ \\
\hline & $\begin{array}{l}\text { Variação admitida da } \\
\text { temperatura entre } \\
\text { centro e bordas do } \\
\text { corpo de prova }\end{array}$ & $\pm 3^{\circ} \mathrm{C}$ & Não estabelecido & Não estabelecido \\
\hline \multirow{5}{*}{$\begin{array}{l}\text { Resfriamento } \\
\text { com água }\end{array}$} & Temperatura da água & $\begin{array}{l}\text { Indefinida, porém até } \\
\text { atingir a temperatura } \\
\text { superficial do corpo de } \\
\text { prova }(20 \pm 5)^{\circ} \mathrm{C}\end{array}$ & $\leq 30^{\circ} \mathrm{C}$ & $(15 \pm 5)^{\circ} \mathrm{C}$ \\
\hline & Quantidade de água & Indefinida & $3,79 \mathrm{~L} / \mathrm{min}$ & $\begin{array}{c}\geq 1,0 \mathrm{~L} / \mathrm{m}^{2} \mathrm{~min}, \mathrm{o} \\
\text { que equivale a } \\
\text { aproximadamente } 6 \\
\mathrm{~L} / \mathrm{min}\end{array}$ \\
\hline & Tempo de aspersão & $\begin{array}{c}\text { Indefinido, mas até } \\
\text { atingir a temperatura } \\
\text { superficial de }(20 \pm 5) \\
{ }^{\circ} \mathrm{C}\end{array}$ & $2 \mathrm{~h} 55 \mathrm{~min}$ & $1 \mathrm{~h}$ \\
\hline & $\begin{array}{l}\text { Distribuição sobre a } \\
\text { superfície }\end{array}$ & Uniforme & Uniforme & Uniforme \\
\hline & $\begin{array}{c}\text { Temperatura após } \\
\text { resfriamento do corpo } \\
\text { de prova }\end{array}$ & $(20 \pm 5)^{\circ} \mathrm{C}$ & Não estabelecido & Não estabelecido \\
\hline \multirow[t]{3}{*}{ Ciclos } & Tempo de cada ciclo & $\begin{array}{l}\text { Aproximadamente } 6 \mathrm{~h} \text {, } \\
\text { porém depende da } \\
\text { composição da parede }\end{array}$ & $6 \mathrm{~h}$ & $6 \mathrm{~h}$ \\
\hline & Quantidade de ciclos & 10 & 25 & 80 \\
\hline & Intervalo entre ciclos & Não estabelecido & $5 \min$ & $2 \mathrm{~h}$ \\
\hline \multirow[t]{3}{*}{$\begin{array}{c}\text { Corpos de } \\
\text { prova }\end{array}$} & Dimensão & $\begin{array}{c}\geq 3,0 \mathrm{~m}^{2}(1,2 \mathrm{~m} \times 2,5 \\
\mathrm{m})\end{array}$ & $\geq 3,5 \mathrm{~m}^{2}$ & $\geq 6,0 \mathrm{~m}^{2}$ \\
\hline & $\begin{array}{c}\text { Restrição de } \\
\text { movimentação das } \\
\text { bordas }\end{array}$ & Sem restrição & Com restrição & Sem restrição \\
\hline & Cor da superfície & Não estabelecido & $\begin{array}{l}\text { Não estabelecido, pois a } \\
\text { medição da temperatura } \\
\text { máxima de ensaio é feita } \\
\text { sobre placa de referência, } \\
\text { portanto a cor da } \\
\text { superfície do corpo de } \\
\text { prova não influi no ensaio }\end{array}$ & Não estabelecido \\
\hline
\end{tabular}


Quanto à definição da cor das superfícies, nenhuma das normas estudadas trata do assunto. Ressalte-se que, dessa forma, as superfícies expostas com cores claras demorarão mais tempo para alcançar a temperatura máxima em relação às cores médias e escuras, problema eliminado com a medição indireta. Portanto, a situação mais crítica refere-se àquelas cujas superfícies têm cores médias e escuras (absortância $\geq 0,5$ ), nas quais a superfície seria aquecida mais rapidamente, resultando em maior gradiente de temperatura em relação ao núcleo do elemento de vedação e, consequentemente, maior gradiente de tensões.

Ainda com relação à cor da superfície exposta do trecho de parede a ser ensaiado, observa-se, por exemplo, que em São Paulo (latitude $23^{\circ} \mathrm{Sul}$ ) os valores médios diários de radiação incidente nos planos horizontais se encontram em $684,8 \mathrm{~W} / \mathrm{m}^{2}$ (FROTA, 2004), enquanto em Paris (latitude $49^{\circ}$ Norte) os valores médios diários se encontram em $356,9 \mathrm{~W} / \mathrm{m}^{25}$ o que demonstra as diferenças de calor e radiação presentes em cada uma dessas regiões e justifica a maior temperatura superficial adotada pela norma brasileira. Guimarães et al. (2002), Granja e Labaki (2003) e Frota (2004) mostraram que a temperatura superficial de uma fachada com cor média ou escura (absortância $\geq$ 0,5) no Brasil pode chegar até a $80^{\circ} \mathrm{C}$. Assim, considera-se que a temperatura máxima de ensaio de $80^{\circ} \mathrm{C}$ é adequada para a situação brasileira. Entretanto, existem revestimentos poliméricos, como o siding de PVC, cuja temperatura de distorção (HDT) é menor do que $80^{\circ} \mathrm{C}^{6}$. Para essas situações, ou outras nas quais possa haver limitação de cor superficial, sugere-se limitar a temperatura máxima do ensaio, no caso da medição feita diretamente na superfície do corpo de prova, porém condicionando que o revestimento somente possa ser utilizado em cores claras (absortância < 0,3). A Diretriz SiNAT 004 (MINISTÉRIO..., 2010) e a Diretriz SiNAT 010 (MINISTÉRIO..., 2014) estabelecem esses limites com relação à temperatura máxima do ensaio de choque térmico, prevendo-se apenas a adoção de cores claras em paredes de fachada.

\section{Aspectos relativos ao aquecimento}

$\mathrm{Na}$ norma brasileira, assim como na Diretriz ETAG 004 (EUROPEAN..., 2008), o nível máximo de energia mantido na fase aquecida é definido pela temperatura superficial da parede, ou seja, a medição da temperatura é feita diretamente

${ }^{5}$ Disponível em: <http://www.satel-light.com/indexeS.htm>. Acesso em: 15 jul. 2014.

${ }^{6}$ Disponível em: <http://www.pvc.org/en/p/heat-distortiontemperature-softening-temperature>. Acesso em: 15 jul. 2014. sobre a superfície do corpo de prova ensaiado. Já na C1185-8 (AMERICAN..., 2012), a medição da temperatura é efetuada com uma placa negra de referência (standard black thermometer), cuja adoção é interessante, pois padroniza a energia incidente sobre a superfície da fachada, independentemente de sua coloração, o que acaba acontecendo na realidade, ou seja, a radiação solar atinge da mesma forma todas as superfícies, independentemente do material, cor ou textura.

A radiação máxima que pode incidir sobre a superfície da vedação pode ser calculada em função da latitude e da orientação em relação aos eixos cardiais da vedação (FROTA, 2004). Já a temperatura que esta fachada pode atingir dependerá de outros fatores, tais como absortância da superfície (relacionada com a cor da superfície), condutividade e emissividade térmica do material, e presença de correntes de vento. Portanto, medir a temperatura superficial através de uma placa negra de referência é mais próximo da situação real, visto que a energia incidente na superfície da parede é a mesma para qualquer tipo de parede.

Verificou-se na realização de ensaios coordenados pelos autores deste artigo que o aquecimento pode levar um tempo relativamente menor quando a vedação é constituída de elementos leves, ou seja, aquela com massa inferior a $60 \mathrm{~kg} / \mathrm{m}^{2}$. Por outro lado, constatou-se o dispêndio de várias horas sob incidência de radiação com potência superior a 4.000 Watts por $\mathrm{m}^{2}$ para vedações consideradas pesadas $\left(>100 \mathrm{~kg} / \mathrm{m}^{2}\right)$. O monitoramento desses ensaios mostrou que, no corpo de prova que demora mais para atingir a temperatura de ensaio, foi aplicada maior energia que no corpo de prova que atingiu a temperatura superficial em menor tempo, gerando tensões na parede que podem não ocorrer na realidade, pois a energia incidente nas diferentes paredes deveria ser a mesma, o que justifica a adoção da medição da temperatura indireta, ou seja, sobre uma placa de referência. Entretanto, estudos ainda precisam ser realizados para definir qual seria a temperatura dessa placa de referência, uma vez que no Brasil, como exposto no item anterior, a temperatura superficial de uma fachada com cor escura (absortância $\geq 0,7$ ) pode chegar a $80^{\circ} \mathrm{C}$, dependendo da localização geográfica.

Outro aspecto a ser analisado diz respeito à quantidade de energia a ser irradiada sobre a superfície do corpo de prova, ou seja, considerar ou não um fator de majoração em função de se estar tratando de um ensaio de envelhecimento acelerado. Portanto, apesar de se considerar que o uso da placa negra de referência é mais adequado, ainda não há parâmetros precisos para sua adoção, cogitando-se, inclusive, admitir diferentes 
temperaturas e/ou tempos de exposição em função da região brasileira em que a obra será implantada.

Quanto ao tempo para atingir a temperatura de aquecimento máxima, em ensaios que não consideram a medição em placa negra de referência, a NBR 15575-4 (ABNT, 2013b) determina a máxima temperatura que a superfície exposta do corpo de prova deve atingir, e um período de tempo de $1 \mathrm{~h}$ para permanência nessa temperatura, para então submeter o corpo de prova ao resfriamento brusco (choque térmico). Entretanto, a referida norma não determina o tempo necessário para se atingir a temperatura máxima da superfície da parede, o que pode variar muito entre paredes com materiais e cores diferentes. Já na diretriz ETAG 004 (EUROPEAN..., 2008) o tempo para que o corpo de prova atenda ao limite da temperatura é definido como $1 \mathrm{~h}$, visto que essa diretriz é específica para um sistema de revestimento.

Assim, como o objetivo é estabelecer uma temperatura-limite para a superfície do corpo de prova, independentemente do tipo de fachada adotada, para o caso brasileiro não se recomenda normalizar o tempo para elevar a temperatura da superfície do corpo de prova. Entretanto, visando não gerar tensões extras nos trechos de fachadas ensaiados, principalmente naquelas leves e formadas por multicamadas, propõe-se o estabelecimento de um tempo mínimo de $1 \mathrm{~h}$, conforme ETAG 004 (EUROPEAN..., 2008), para que a temperatura máxima da superfície do corpo de prova seja atingida.

Além disso, é recomendável estabelecer durante quanto tempo o corpo de prova permanecerá aquecido antes de sofrer o resfriamento brusco. A NBR 15 575-4 (ABNT, 2013b) determina o período de $1 \mathrm{~h}$; a C 1185-8 (AMERICAN..., 2012), de 2h55min; e a ETAG 004 (EUROPEAN... (2008), de 2 h. Considera-se que a ASTM determine um tempo maior porque a placa negra de referência atinge rapidamente a temperatura máxima, enquanto a superfície do corpo de prova levaria mais tempo para atingir essa temperatura; além disso, a temperatura-limite fixada pela ASTM é de $60^{\circ} \mathrm{C}$, enquanto na ETAG e na NBR é $70^{\circ} \mathrm{C}$ e $80^{\circ} \mathrm{C}$ respectivamente.

Considera-se também que, para componentes cimentícios, seja insuficiente o período de $1 \mathrm{~h}$ estabelecido na norma brasileira para manter o corpo de prova aquecido, pois, segundo Fontenelle (2012), a perda de umidade de componentes cimentícios, quando expostos a altas temperaturas, não estabiliza antes de $1 \mathrm{~h}$ de ensaio, conforme mostra a Figura 3, que registra a variação dimensional de chapas cimentícias durante a realização de ensaio de ação de calor e choque térmico em paredes. A análise da figura mostra que inicialmente (nos primeiros $22 \mathrm{~min}$ de ensaio) houve expansão da chapa pela dilatação térmica e, posteriormente, estabilização seguida de retração, atribuída à perda de umidade. Entretanto, não foi verificada a estabilização dimensional da chapa durante a fase aquecida, não sendo possível, portanto, afirmar que a placa não continuaria a se retrair caso o tempo fosse ampliado. Por isso, considera-se que a C 1185-8 (AMERICAN..., 2012) estabelece que a superfície fique aquecida por 2 h55 min, recomendando-se para a norma brasileira a ampliação do período da fase aquecida.

Figura 3 - Média das variações dimensionais das chapas cimentícias verificadas durante o ensaio de choque térmico

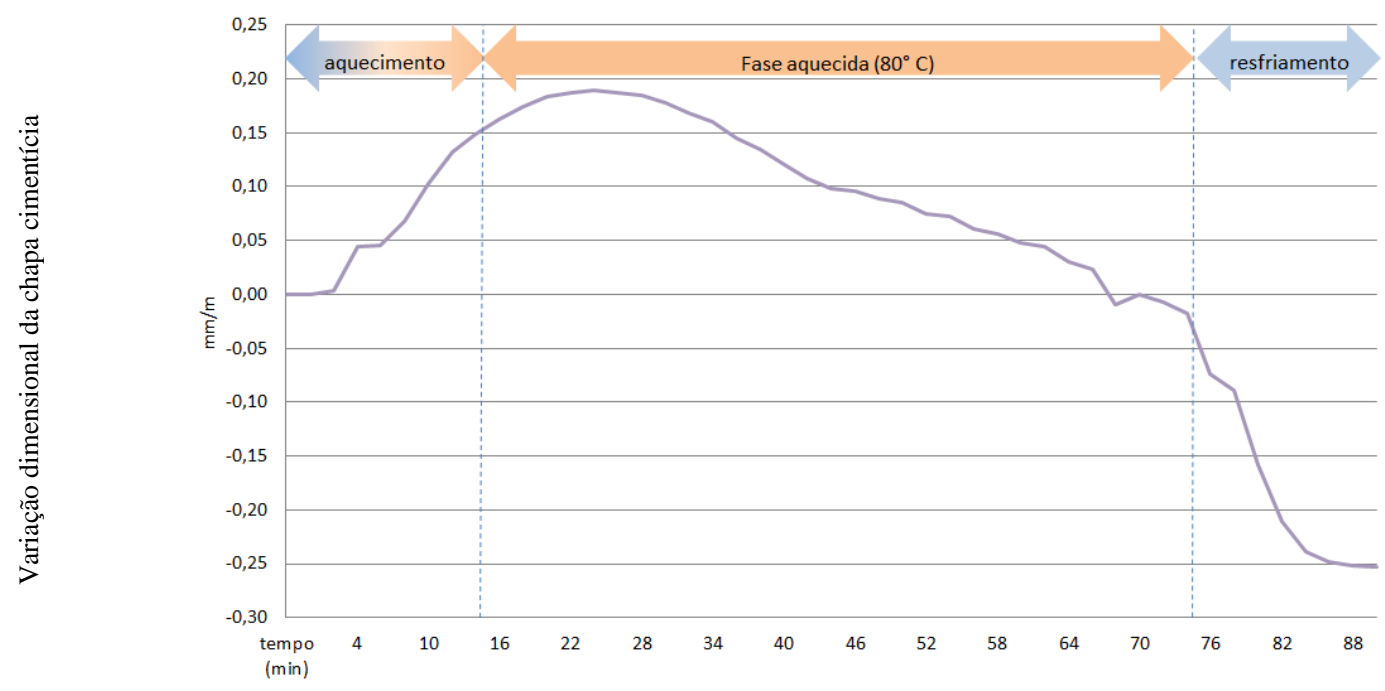

Fonte: adaptado de Fontenelle (2012). 


\section{Considerações finais}

Com base nas análises das normas técnicas consideradas neste artigo, nos resultados obtidos nos experimentos realizados, no histórico de resultados disponíveis aos autores do presente artigo e em discussões já realizadas no Comitê Técnico do SiNAT, constata-se que o método de ensaio de ação de calor e choque térmico previsto na norma técnica brasileira pode ser aprimorado, considerando novos parâmetros, procedimentos ou condições para a realização do referido ensaio, quais sejam:

(a) alteração do comprimento do corpo de prova para, no mínimo, $2,40 \mathrm{~m}$, considerando sua altura equivalente à do pé-direito, de pelo menos, 2,50m; nesta condição, a área mínima do corpo de prova é de $6,0 \mathrm{~m}^{2}$;

(b) adoção no corpo de prova de todos os detalhes característicos do sistema construtivo, inclusive juntas, de forma a torná-lo o mais representativo possível da situação real de aplicação;

(c) adoção de vinculação lateral ou de dispositivo que simule continuidade do corpo de prova nas laterais, de forma a restringir parcialmente sua movimentação;

(d) manutenção dos vínculos atualmente previstos para a base e o topo do corpo de prova, considerando-o apoiado no piso e articulado no topo; se houver condições específicas de vinculação para o elemento de fachada, impostas pelo produtor para o sistema de vedação, tais condições devem ser representadas no ensaio;

(e) adoção de dois patamares de temperatura máxima no ensaio, para a situação de medição direta, considerando-se o valor de $(80 \pm 3)^{\circ} \mathrm{C}$ nas condições usuais e de $(60 \pm 3)^{\circ} \mathrm{C}$ nos casos de limitação expressa de temperatura máxima a ser submetido o produto, condicionando a adoção de cores claras na superfície de fachadas (por exemplo, com absortância à radiação solar menor ou igual a 0,3$)$

(f) adoção de um tempo mínimo de $1 \mathrm{~h}$ para que a temperatura máxima da superfície do corpo de prova seja atingida, também para a situação de medição feita diretamente na superfície do corpo de prova; e

(g) aumento de $1 \mathrm{~h}$ para $2 \mathrm{~h}$ no período ou patamar de manutenção da temperatura máxima na fachada antes do resfriamento brusco.

Outros aspectos, como definição da quantidade de energia incidente, se majorada ou não, em função de o ensaio de choque térmico ser considerado de envelhecimento acelerado, poderiam ser aqui analisados, mas necessitam ainda de outros estudos para que possam ser adequadamente considerados como propostas de alteração da norma brasileira. Essa definição da quantidade de energia influi diretamente no estabelecimento do número de ciclos de aquecimento e resfriamento a ser adotado nos ensaios. Como não foram realizados estudos variando-se o número de ciclos, por enquanto permanecem os dez ciclos previstos na NBR 15575-4 (ABNT, 2013b).

Aspecto que também merece atenção é a adoção da medição da temperatura de ensaio em placa negra (placa de referência). Entretanto, estudos ainda precisam ser realizados para definir qual seria a temperatura dessa placa de referência, relacionando-a com a localização geográfica.

Não foi discutida a quantidade de água a ser aspergida no processo de resfriamento, mas sugere-se padronizar o valor de $3 \mathrm{~L} / \mathrm{m}^{2} x \min$, vazão esta adotada no ensaio de estanqueidade à água de paredes externas, conforme previsto na NBR 15575-4 (ABNT, 2013b). Quanto à temperatura da água para resfriamento, esta deve ser capaz de reduzir a temperatura superficial do corpo de prova de $80^{\circ} \mathrm{C}$ ou $60^{\circ} \mathrm{C}$ para $(20 \pm 5)^{\circ} \mathrm{C}$.

\section{Referências}

AMERICAN SOCIETY FOR TESTING AND MATERIALS.ASTM C 1185-8: standard test methods for sampling and testing non-asbestos fiber-cement flat sheet, roofing and siding shingles, and clapboards. Philadelphia, 2012.

ARNOULT, J.; KREMP, V.; MUSEMBI, M. (Eds.).Proceeding of the Pan-African Conference on the Preservation and Conservation of Library and Archival Materials.Headquarters: University of Virginia, 1995.

ASSOCIAÇÃO BRASILEIRA DE NORMAS TÉCNICAS. NBR 15575-1: edificações habitacionais: desempenho: parte 1: requisitos gerais. Rio de Janeiro, 2013a.

\section{ASSOCIAÇÃO BRASILEIRA DE NORMAS}

TÉCNICAS. NBR 15575-4: edificações

habitacionais: desempenho: parte 4: requisitos para os sistemas de vedações verticais internas e externas - SVVIE. Rio de Janeiro, 2013b.

\section{AUSTRALIAN NEW ZEALAND}

STANDARD.AS/NZS 2908: cellulose cementproducts: corrugated sheets. Sidney, 2000.

DANIOTTI, B.; CECCONI, F. R. CIB W080: test methods for service life prediction. Disponível em: <http://cibworld.xs4all.nl/dl/publications/w080_w g3_report.pdf>. Acesso em: 08 dez. 2014. 
DIAS, C. M. R. Efeitos do Envelhecimento na Microestrutura e no Comportamento Mecânico dos Fibrocimentos. São Paulo, 2005. 125 f.

Dissertação (Mestrado em Engenharia Civil) Escola Politécnica, Universidade de São Paulo, São Paulo, 2005.

ESQUIVEL, T. J. F. Avaliação da Influência do Choque Térmico na Aderência dos

Revestimentos de Argamassa. São Paulo, 2009.

262 f. Tese (Doutorado em Engenharia Civil) -

Escola Politécnica, Universidade de São Paulo, São Paulo, 2009.

\section{EUROPEAN ORGANISATION FOR} TECHNICAL APPROVALS.ETAG 004:

Guideline for European Technical Approval of External Thermal Insulation Composite Systems WithRendering. Brussels,

2008.Disponívelem:<http://www.ue.itb.pl/files/ue/ etag/etag_004.pdf >. Acesso em: 08 dez. 2014.

FONTENELLE, J. H. Sistema de Fixação e Juntas em Vedações Verticais Constituídas Por Placas Cimentícias: estado da arte, desenvolvimento de um sistema e avaliação experimental. São Paulo, 2012. 219 f. Dissertação (Mestrado em Engenharia Civil) - Escola Politécnica, Universidade de São Paulo, São Paulo, 2012.

FROTA, A. B. Geometria da Insolação. São Paulo: Geros, 2004.

GRANJA, D. A.; LABAKI, L. C. Influence of External Surface Color on the Periodic Heat Flow Through a Flat Solid Roof With Variable Thermal Resistance. International Journal of Energy

Research, v. 27, n. 8, p. 771-779, 2003.

GRICIUTE், G.; BLIUDZIUS, R.;

NORVAISIENE, R. The Durability Test Method for External Thermal Insulation Composite System (ETICS) Used in Cold and Wet Climate Countries. Journal of Sustainable Architecture and Civil Engineering, v. 1, n. 2, 2013.

GUIMARÃES, L. E. et al.Acompanhamento das Variações das Temperaturas Superficiais dos Principais Materiais Utilizados em Fachadas.In: ENCONTRO SOBRE PESQUISAS DE MATERIAIS DE CONSTRUÇÃO, 2., Goiás, 2002. Anais... Goiás, 2002.
INTERNATIONAL ORGANIZATION FOR STANDARDIZATION.ISO 15686-6: building and constructed assets: service life planning: part 6: procedures for considering environmental impacts. Geneva, 2004.

INTERNATIONAL ORGANIZATION FOR STANDARDIZATION.ISO 8336: fbre-cement flat sheets.Geneva, 2009.

JOHN, V. M. et al.Durabilidade e

Sustentabilidade: desafios para a construção civil brasileira. In: WORKSHOP SOBRE

DURABILIDADE DAS CONSTRUÇÕES, 2., São José dos Campos, 2002. Anais... São José dos Campos, 2002.

JOHN, V. M.; SATO, N. M. N. Durabilidade de Componentes da Construção. 2006. Disponível em: <http://www.habitare.org.br/publicacoes_coletanea 7.aspx>. Acesso em: $08 \mathrm{dez} .2014$.

LEWRY, A. J.; CREWDSON, L. F. E. Approaches to Testing the Durability of Materials Used in the Construction and Maintenance of Buildings.Construction and Building Materials, v. 8, n. 4, p. 211-222, 1994.

\section{MINISTÉRIO DAS CIDADES. Diretriz SiNAT}

004: sistemas construtivos formados por paredes estruturais constituídas de painéis de PVC preenchidos com concreto. 2010. Disponível em <http://www.cidades.gov.br/pbqph/projetos_SiNAT.php>. Acesso em: 08 dez. 2014. MINISTÉRIO DAS CIDADES. Diretriz SiNAT 003: revisão 01: sistemas construtivos formados por paredes estruturais constituídas de painéis de PVC preenchidos com concreto. 2012. Disponível em:<http://www.cidades.gov.br/pbqph/projetos_sinat.php>. Acesso em: 08 dez. 2014.

MINISTÉRIO DAS CIDADES. Diretriz SiNAT 010: sistemas construtivos formados por paredes estruturais constituídas de painéis de PVC preenchidos com concreto. 2014. Disponível em <http://www.cidades.gov.br/pbqph/projetos_sinat.php>. Acesso em: 08 dez. 2014. 


\section{Luciana Alves Oliveira}

Centro Tecnológico do Ambiente Construído | Instituto de Pesquisas Tecnológicas do Estado de São Paulo | Av. Prof. Almeida Prado, 532, Butantã | São Paulo - SP - Brasil | CEP 05508-901 | Tel.: (11) 3767-4164 | E-mail: luciana@ipt.br

João Heitzmann Fontenelle

Centro Tecnológico do Ambiente Construído | Instituto de Pesquisas Tecnológicas do Estado de São Paulo | Tel.: (11) 3767-4556 |

E-mail: jhfonte@ipt.br

\section{Claudio Vicente Mitidieri Filho}

Centro Tecnológico do Ambiente Construído | Instituto de Pesquisas Tecnológicas do Estado de São Paulo | Tel.: (11) 3767-4164 |

E-mail: claumit@ipt.br

Revista Ambiente Construído

Associação Nacional de Tecnologia do Ambiente Construído

Av. Osvaldo Aranha, $99-3^{\circ}$ andar, Centro

Porto Alegre - RS - Brasil

CEP $90035-190$

Telefone: +55 (51) 3308-4084

Fax: +55 (51) 3308-4054

www.seer.ufrgs.br/ambienteconstruido

E-mail: ambienteconstruido@ufrgs.br 